\title{
Endogenous Growth and South-North Trade
}

\author{
Youngwan Goo \\ SAMSUNG Research Institute of Finance
}

Seonghoon Lee

US Bureau of Census

\begin{abstract}
In this article, we develop an endogenous growth model to analyze the impact of knowledge spillovers, the disparity in initial endowments and production technologies on economic growth of two trading regions. We found that the growth rates of technology development of the two regions become uneven unless they have an identical initial steady-state labor allocation between technology development and intermediate inputs. Trade in intermediate goods and knowledge spillovers improve welfare in both regions.
\end{abstract}

- JEL Classifications: D43, F12, L13, O12, O30

- Key Words: Endogenous Growth, Monopolistic Differentiated Product Market; Even (Equal) and Uneven (Unequal) Growth, Knowledge Spillover

\section{Introduction}

Over the last two decades, there has been a growing body of theoretical studies focusing on the impact of trade on endogenous economic growth. However, the results obtained from the many studies are conflicting. One set of studies has shown that trade between two regions results in uneven economic growth. Other studies have found just the opposite. Studies that found uneven growth rates

*Corresponding address: Youngwan Goo, SAMSUNG Research Institute of Finance, Chief Research Fellow $15^{\text {th }}$ F1., Taepyeongro Bldg. 310, Taepyeongro 2-Ga, Jung-Gu, Seoul, Korea 100-102. Tel: $+82-$ 2-3706-7436, Fax: +82-2-3706-7488, E-mail: ywgoo@mail.posri.re.kr

Seonghoon Lee, Center for Economic Studies, U.S. Bureau of the Census, E-mail: lee00318@ @es.census.gov (C)2002-Center for International Economics, Sejong Institution, All Rights Reserved. 
focused on non-tradable knowledge and human technology, such as: (i) the disparity in initial endowment (Krugman, 1991, Matsuyama, 1991); (ii) the difference in human capital accumulation (Azariadis and Drazen, 1990, Becker et al., 1990, Stokey, 1991, Buiter and Kletzer, 1991); and (iii) learning by doing (Boldrin and Scheinkman, 1988, Krugman, 1987, Lucas, 1988, Young, 1991). Studies that result in even growth rates generally have been based on assumptions such as (i) similar technologies between the two regions (Azariadis and Drazen, 1990); (ii) the possibility of knowledge spillovers (Grossman and Helpman, 1990, 1991 Feenstra, 1996); (iii) imitation and diffusion (Krugman, 1987, Segerstrom et al., 1990, RiveraBatiz and Romer, 1991a, 1991b); and (iv) balance of trade (Goo and Park, 1999).

The models that illustrated even growth rates depend on the crucial assumption of steady state equilibrium with constant prices, equal labor forces, balance of trade, and/or knowledge spillovers between the two regions. Devereux and Lapham (1994), however, argued that the knowledge-driven models with identical endowments and production technologies between two trading regions leading to even growth rate are unstable unless the stocks of knowledge of the two regions are exactly equal prior to trade. In the light of this argument, this paper goes back to the basic assumptions underlying even/uneven growth rates. We consider a knowledge-driven model with different endowments and production technologies between two trading regions. We then show that as long as the initial share of a steady state labor allocation is the same in two trading regions, the balanced growth rates are equalized in the long run. ${ }^{1}$

The organization of the paper is as follows. In section 2, we describe a basic model of trade. Section 3 presents a simple general equilibrium model. In section 4 , the balanced growth path is derived in a steady state after trade, considering tradable/non-tradable intermediate goods. It also discusses the results and demonstrates how and why the growth rates of technology development can be even or uneven. Section 5 analyzes the effects of trade in intermediate goods and knowledge spillovers on welfare. Section 6 concludes the paper.

\section{The Model}

We consider an economy with two regions: the South and the North. On the

\footnotetext{
This result will hold for the cases such as: (1) the intermediate goods are tradable/non-tradable between two regions; (2) all firms face constant transportation costs in moving their goods across their regions; (3) knowledge diffuses perfectly/imperfectly across regions. If we consider constant transportation costs, there is a level effect but no growth effect.
} 
consumption side, we assume that both regions have the same taste parameters for product varieties. Consumers in both regions are allowed to have identical, homothetic preferences. A time-separable utility function of a representative consumer in region $j$ is given by

$$
U^{j}(t)=\int_{t}^{\infty} e^{-\rho(\tau-t)} \log u^{j}\left(C_{N}^{j}(\tau), C_{S}^{j}(\tau)\right) d \tau, \text { for } j=N \text { or } S
$$

where $\rho$ is the subjective discount rate; $N$ and $S$ denote North and South, respectively. From now on, the superscripts denote the regions where goods are consumed, while the subscript denote the regions where goods are produced. $C_{k}^{j}(\tau)$ is the consumption of the final goods produced by region chosen by consumer in region $k$ at $j$ time $\tau$. As in Grossman and Helpman (1990), this consumer's maximization problem can be solved in two stages. In the first stage, we derive an indirect utility function by solving consumers maximization of static utility for a given level of expenditure at time $t$. In the second stage, we can solve the optimal pattern of expenditure. Let the instantaneous subutility function $u^{i}$ $\left(C_{N}^{j}(t), C_{S}^{j}(t)\right)$ be of a CES form such that $u^{j}=\left[\left[C_{N}^{j}(t)\right]^{\sigma}+\left[C_{S}^{j}(t)\right]^{\sigma}\right]^{\sigma}$, for $0<\sigma<1$, where $1 /(1-\sigma)$ is the elasticity of substitution. Because the instantaneous subutility function $u^{j}\left(C_{N}^{j}(t), C_{S}^{j}(t)\right)$ is homogenous of degree one, an indirect utility function can be written as $f^{j}(t)=v\left(P_{Y, N}(t), P_{Y, S}(t)\right) M^{j}(t)$, where $P_{Y, k}(t)$ denotes the price of final goods produced by region $k$ at time $t$ and $M^{j}(t)$ denotes a consumer's given level of expenditure in region $j$ at time $t$. From the first stage consumer's utility maximization problem, the consumption of final goods produced by region $k$ chosen by consumer in region $j$ at time $i$ can be written as

$$
C_{k}^{j}(t)=\left[\frac{M^{j}(t)}{P_{Y, k}(t)}\right]^{\frac{1}{1-\sigma}}\left[u^{j}(t)\right]^{\frac{\sigma}{1-\sigma}}
$$

Equation (1) shows that $C_{k}^{j}(t)$ is positively related to $M^{j}(t)$ and negatively related to $P_{Y, k}(t)$. Plugging equation (1) into $u^{j}\left(C_{N}^{j}(t){ }_{1}{ }_{1} C_{\delta}^{j}(t)\right)$ yields the indirect utility function: $f^{j}(t)=\left[\left[P_{Y, N}(t)\right]^{\frac{-\sigma}{1-\sigma}}+\left[P_{Y, S}(t)\right]^{\frac{-\sigma}{1-\sigma}}\right]^{\frac{1-\sigma}{\sigma}} M^{j}(t)$. In the second stage, the representative consumer in region $j$ at time $t$ chooses the time pattern of expenditures in order to maximize

$$
V^{j}(t)=\int^{\infty} e^{-\rho(\tau-t)}\left\{\left[\log \left[P_{Y, N}(\tau)\right]^{\frac{-\sigma}{1-\sigma}}+\left[P_{Y, S}(\tau)\right]^{\frac{-\sigma}{1-\sigma}}\right]^{\frac{1-\sigma}{\sigma}}+\log M^{j}(\tau)\right\} d \tau,
$$

subject to a budget constraint given by 


$$
\int^{\infty} e^{-R(\tau)} M^{j}(\tau) d \tau \leq \int^{\infty} e^{-R(\tau)} w_{j}(\tau) L_{j} d \tau+a_{j}(t)
$$

where $R(\tau)=\int r(h) d h, r(h)$, is the interest rate at time $h, w_{j}(\tau)$ is the wage rate of the representative consumer in region $j, L_{j}$, is the consumer's labor supply, and $a_{j}(t)$ is the value of the consumer's asset at time $t$. Assuming that capital market is integrated, consumer's in both regions face a common interest rate. The necessary condition for the maximization problem gives the optimal path for expenditure,

$$
\frac{\dot{M}}{M}=\frac{\dot{M}^{N}}{M^{N}}=\frac{\dot{M}^{S}}{M^{S}}=r(t)-\rho
$$

Equation (2) shows that the growth rate of consumer's expenditure is positive (negative) if interest rate of the integrated capital market is greater (less) than the consumers subjective discount rate.

On the production side, each region produces final goods, $Y$, and intermediate goods, $x$. Each region also develops technologies, $A$. The final goods are produced by intermediate inputs, whereas all intermediate inputs and new blueprints are produced by employing labor. New intermediate products are imperfect substitutes for existing products, which are imperfect substitutes themselves. That is, the technology of producing final goods exhibits imperfect substitution among intermediate inputs and thereby this degree of substitutability will generate the degree of competition in the intermediate goods market. Moreover, each producer of intermediate input producer is differentiated from others in the sense that they can solely access their own blueprints and thus can maintain their monopoly power. The level of the technologies developed in the North is different from that in the South. Let $A_{N}$ be the level of the technologies developed in the North and $A_{S}$ be that in the South. Intermediate goods may or may not be tradable. When intermediate goods are not tradable, in order for the North (South) to produce final goods, the North (the South) will use intermediate goods produced only in the North (South). When intermediate goods are tradable, each region can use intermediate goods produced from the other region for final goods production. The production functions for final goods in both regions are $C E S$ production functions such that only intermediate goods are used as inputs. Let $Y_{k}$ be the output of final goods produced in region $k$. The production function of the final goods in region $k$ is

$$
Y_{k}=\left[\int_{i=0}^{A_{k}}\left[x_{i, k}^{k}\right]^{\mu} d i+\theta \int_{i=0}^{A_{j}}\left[x_{i, j}^{k}\right]^{\mu} d i\right]^{\frac{1}{\mu}} \text { for } k=N \text { or } S, \text { and } k \neq j,
$$


where $0<\mu<1$ and $\theta$ is 0 or 1 . Here, $x_{i, j}^{k}$ denotes the input demanded in region $k$ for intermediate goods $i$ produced in region $j$, and $\theta=0$ corresponds to nontradable intermediate goods while $\theta=1$ corresponds to completely tradable intermediate goods. The profit function for final goods in region $k$ becomes $\Pi_{Y, k}=P_{Y, k} Y_{k}-\left[\int_{i=0}^{A_{k}} P_{i, k}^{k} x_{i, k}^{k} d i+\theta \int_{i=0}^{A_{j}} P_{i, j}^{k} x_{i, j}^{k} d i\right]$ where $P_{i, j}^{k}$ is the effective price in region $k$ for intermediate goods $i$ produced in region $j$. From these profit functions, we can derive the optimal allocations. The necessary conditions for optimal $x_{i, j}^{k}$ in region $k$ becomes

$$
P_{Y, k}\left[Y_{k}\right]^{1-\mu}\left[x_{i, j}^{k}\right]^{-[1-\mu]}=P_{i, j}^{k} \text {, for } \forall i \in\left[0, A^{N}\right] \cup\left[0, A^{S}\right] .
$$

Let $1 / \beta$ be the unit labor requirement for producing intermediate goods. That is, the production function of intermediate goods in each region is $x_{i, k}=\beta_{k}, l_{i, k}$ where $x_{i, k}=x_{i, k}^{k}+\theta x_{i, k}^{j}$, for $\theta=0$ or 1 , denotes the quantity of intermediate input $i$ produced in region $k$, and $l_{i, k}$ denotes the labor input employed in producing intermediate input $i$ in region $k$. Since the demand elasticity for the intermediate goods is $1 /(1-\mu)$ in both regions, the monopoly prices for intermediate goods become $P_{i, k}^{N}=P_{i, k}^{S}=\frac{w_{k}}{\beta_{k} \mu}$, which is the constant markup over the marginal costs. With this monopoly price for intermediate goods and the derived demand functions for intermediate goods given by equation (4), we can derive the optimal allocations of $x$ 's in terms of the level of final goods and the set of prices, which is given by $x_{i, j}^{k}=\left[\frac{w_{j}}{\beta_{j} \mu}\right]^{\frac{1}{1-\mu}} Y_{k}\left[P_{Y, k}\right]^{\frac{1}{1-\mu}}$. Plugging these optimal allocations into the production function of final goods given by equation (3) yields the price function of final goods

$$
P_{Y, k}=\left[A_{k}\left[\frac{w_{k}}{\beta_{k} \mu}\right]^{\frac{\mu}{1-\mu}}+\theta A_{j}\left[\frac{w_{j}}{\beta_{j} m}\right]^{\frac{\mu}{1-\mu}}\right]^{\frac{1-\mu}{\mu}}, \text { for } k \neq j
$$

This price function of final goods shows that an increase in the level of technologies or trade in intermediate goods between the two regions leads to a decrease in the price of final goods, while an increase in wage rate raises the price of final goods.

In addition, with the effective monopoly price for intermediate goods, the profit function for intermediate goods in each region is

$$
\Pi_{i, k}=\Pi_{i, k}^{N}+\Pi_{i, k}^{S}=\frac{[1-\mu] w_{k} X_{k}}{\beta_{k} \mu A_{k}},
$$


where $X_{k}=\int_{0}^{A_{k}} x_{i, k} d i$ is the aggregate output of intermediate goods in region $k$.

The level of technologies in each region evolves

$$
\dot{A}_{k}=\varphi_{k}\left[A_{k}+\delta A_{j}\right] L_{A, k}, \text { for } 0 \leq \delta \leq 1 \text { and } k \neq j,
$$

where $\varphi_{k}$ is a productivity parameter,$L_{A, k}$ is the total labor input used for the technology development in region $k$, and $\delta$ denotes the degree of knowledge flow across regions. If $\delta=0$, then there are no knowledge spillovers between the two regions. However, if $\delta=1$, then there exist perfect knowledge spillovers. Suppose that there are no knowledge spillovers. Then, these technologies are nonexcludable within the same region, but excludable between the two regions. If knowledge spillovers are non-excludable both within and between the regions, then anyone engaged in new technologies can freely access the entire stock of technologies existing in both regions. Let $P_{A, k}$ be the price of the new technology developed in region $k$, then the profit function for this new technology in region $k$ is $\Pi_{A, k}=P_{A, k} \dot{A}-w_{k} L_{A, k}$. The necessary condition for the optimal new technology development requires marginal revenue be equal to marginal cost in region $k$

$$
P_{A, k} \frac{\dot{A}_{k}}{L_{A, k}}=P_{A, k} \varphi_{k}\left[A_{k}-\delta A_{j}\right]=w_{k}
$$

The price of new technology developed in region $k$ is the expected future profits discounted by the market interest rate, so that $P_{A, k}(t)=\int_{i}^{\infty} e^{-R(\tau)}\left[\Pi_{i, k}(\tau)\right] d \tau$. The no-arbitrage conditions for investment in new technology development can be obtained by differentiating this equation with respect to time $t$

$$
\dot{P}_{A, k}(t)=-\Pi_{i, k}(t)+r(t) P_{A, k}(t) .
$$

As Grossman and Helpman (1990) mentioned, this no-arbitrage condition implies that the interest rate is equal to instantaneous profit over the cost of new technology development (dividends) and the rate of change in the price of new technology development (capital gains).

\section{General Equilibrium}

We complete the model by stating the market-clearing conditions. First, goods markets are composed of final goods and intermediate goods. We consider an economy in which final goods are tradable between the two regions while 
intermediate goods may or may not be tradable. The output of final goods produced in region $k$ at time $t$ should be equal to the sum of its consumption in both regions at time $t$. The total supply of intermediate goods in each region at time $t$ is equal to the input demand for final goods in both regions at time $t$. The goods market clearing conditions for final goods and intermediate goods become

$$
\begin{gathered}
Y_{k}=C_{k}^{N}+C_{k}^{S}, \\
X_{k}=\int^{A_{k}}\left[x_{i, k}^{k}+\theta x_{j, k}^{j}\right] d i, \text { for } k \neq j .
\end{gathered}
$$

Second, the labor force in each region at time $t$ is devoted to developing new technologies and producing intermediate goods in each region at time $t$. Since labor is assumed to be unmovable across regions, labor market clears when it satisfies the following

$$
\bar{L}_{k}=L_{X, k}+L_{A, k} \text {, where } L_{X, k}=A_{k} l_{i, k} .
$$

Finally, asset market clearing condition implies

$$
a_{k}=P_{A, k} A_{k} \text { for all time } t \text { with } P_{k}(0)=P_{A, k}(0) A_{k}(0) .
$$

From the market clearing condition for final goods, we can get the relation of final goods between the two regions in terms of their relative prices

$$
\frac{Y_{N}}{Y_{S}}=\left[\frac{P_{Y, N}}{P_{Y, S}}\right]^{-\frac{1}{1-\sigma}}
$$

Equation (11) shows that the ratio of North/South final goods is negatively related to their price ratio. Plugging optimal allocations of $x$ 's into the market clearing condition for the intermediate goods yields

$$
X_{k}=A_{k}\left[\frac{w_{k}}{\beta_{k} \mu}\right]^{-\frac{1}{1-\mu}}\left[Y_{k}\left[P_{Y, k}\right]^{\frac{1}{1-\mu}}+\theta Y_{j}\left[P_{Y, j}\right]^{\frac{1}{1-\mu}}\right] \text {, for } k \neq j .
$$

When there is no trade in intermediate goods, i.e., $\theta=0$, with the price function of final goods given by equation (5), the aggregate output of intermediate goods in each region becomes

$$
X_{k}=\left[A_{k}\right]^{-\frac{1-\mu}{\mu}} Y_{k}
$$


When intermediate goods are tradable, i.e., $\theta=0$, the price of final goods becomes equal in the two regions from equation (5). Hence the output of final goods becomes equal in the two regions from equation (11). So, the aggregate output of intermediate goods in each region becomes

$$
X_{k}=2 A_{k}\left[\frac{w_{k}}{\beta_{k} \mu}\right]^{\frac{1}{1-\mu}}\left[P_{Y}\right]^{\frac{1}{1-\mu}} Y,
$$

where $P_{Y}=P_{Y, N}=P_{Y, S}$ and $Y=Y_{N}=Y_{S}$.

If intermediate goods are tradable, the ratio of North/South aggregate output of intermediate goods does not depend on the output of final goods and their prices. It depends on the ratio of aggregate stocks of technology and the relative wage rate. If one region has a higher stock of technology than the other, then the aggregate output of intermediate goods becomes higher. A higher relative wage rate, however, leads to a fall in the aggregate output of intermediate goods because the price of the intermediate goods is a function of the constant markup over the marginal costs (wage rate).

\section{The Balanced Growth Path}

We consider a steady state in which labor allocations remain constant over time. As mentioned earlier, intermediate goods may or may not be tradable between the two regions. In section A, we analyze the balanced growth path in an open economy where intermediate goods are not tradable and there are no knowledge spillovers between the two regions. In section $\mathrm{B}$, we allow intermediate goods to be tradable while knowledge may or may not diffuse between the two regions.

\section{A. Non-Tradable Intermediate Goods}

When intermediate goods are non-tradable (i.e., $\theta=0$ ), it is natural to consider an economy in which there are no knowledge spillovers (i.e., $\delta=0$ ). This economy allows only final goods to be traded between the two regions. When , equation (12b) becomes

$$
\frac{\dot{Y}_{k}}{Y_{k}}=\left[\frac{1-\mu}{\mu}\right] \frac{\dot{A}_{k}}{A_{k}}+\frac{\dot{X}_{k}}{X_{k}}
$$

As technology development growth increases, the growth rate of final goods will increase proportionally to $\left[\varepsilon_{x}-1\right]^{-1}$ times that of technology development, where 
$\varepsilon_{x}$ is the elasticity of demand for intermediate goods. In addition, when $\theta=0$, from equation (5), the relation of the prices of final goods between the two regions becomes $\frac{P_{Y, N}}{P_{Y S}}=\frac{\beta_{S} w_{N}}{\beta_{N} w_{S}}\left[\frac{A_{N}}{A_{S}}\right]^{\frac{1-\mu}{\mu}}$. Substituting this relation into equation (11) yields the following relation of the growth rates of final goods between the two regions

$$
\frac{\dot{Y}_{N}}{Y_{N}}-\frac{\dot{Y}_{S}}{Y_{S}}=-\frac{1}{1-\sigma}\left[\left[\frac{\dot{w}_{N}}{w_{N}}-\frac{\dot{w}_{S}}{w_{S}}\right]-\frac{1-\mu}{\mu}\left[\frac{\dot{A}_{N}}{A_{N}}-\frac{\dot{A}_{S}}{A_{S}}\right]\right]
$$

Note that $\varepsilon_{Y}=1 /(1-\sigma)$ is the elasticity of demand for final goods. If the North's wage rate grows faster than that of the South, then the output of final goods in the South grows faster than in the North proportionally to the elasticity of demand for final goods. For new technology development, the region that grows faster in technology development will also grow faster in final goods proportionally to $\varepsilon_{Y} /\left[\varepsilon_{x}-1\right]$.

From Equations (13) and (14) we get the following relation of the growth rates of new technology development between the two regions in terms of growth relations of wages and the outputs of intermediate goods

$$
\frac{1-\mu}{\mu}\left[\frac{\dot{A}_{N}}{A_{N}}-\frac{\dot{A}_{S}}{A_{S}}\right]=\frac{1}{\sigma}\left[\frac{\dot{w}_{N}}{w_{N}}-\frac{\dot{w}_{S}}{w_{W}}\right]+\frac{1-\sigma}{\sigma}\left[\frac{\dot{X}_{N}}{X_{N}}-\frac{\dot{X}_{S}}{X_{S}}\right]
$$

Equation (15) states that given the growth rates of the aggregate intermediate goods, the region whose wage rate grows faster also has faster growth rate of technology development. When there are no knowledge spillovers, equations (6) and (8) yield $\frac{\Pi_{i, k}}{P_{A, k}}=\frac{1-\mu}{\mu \beta_{k}} \varphi_{k} X_{k}=\frac{1-\mu}{\mu \beta}\left[\frac{X_{k}}{L_{A, k}}\right] \frac{\dot{A}_{k}}{A_{k}}$. So, the no-arbitrage condition for technology development given by equation (9) becomes

$$
\frac{\dot{w}_{k}}{w_{k}}-\frac{\dot{A}_{k}}{A_{k}}=-\frac{1-\mu}{\mu} \varphi_{k} L_{X, k}+r=-\frac{1-\mu}{\mu}\left[\frac{L_{X, k}}{L_{A, k}}\right] \frac{\dot{A}_{k}}{A_{k}}+r,
$$

since $X_{k}=\beta_{k} L_{X, k}$. The left hand side of Equation (16) is the rate of change in the price of new technology development (capital gains) and the first term of the right hand side is the negative of the instantaneous profit over the cost of new technology development (dividends). Equation (16) says the common interest rate is equal to dividends and capital gains. From equations (15) and (16), together with labor market clearing condition given by Equation (10c), the difference in the growth rates of new technology development between the two regions becomes 


$$
\frac{\dot{A}_{N}}{A_{N}}-\frac{\dot{A}_{S}}{A_{S}}=\Delta_{1}\left[\left[\varphi_{N} \bar{L}_{N}-\varphi_{S} \bar{L}_{S}\right]-[1-\sigma]\left[\frac{\dot{X}_{N}}{X_{N}}-\frac{\dot{X}_{S}}{X_{S}}\right]\right]
$$

where $\Delta_{1}=\frac{\varepsilon_{x}}{\varepsilon_{x}-1+1 / \varepsilon_{\gamma}}>0$.

In a steady state where $\dot{X}=0^{2}$, the difference of the growth rates of new technology development between the two regions, given by equation (17a), yields the following proposition.

Proposition 1. (a) In an economy where intermediate goods are not tradable, given $\varphi_{N}=\varphi_{S}$, in a steady state the technology development grows faster in the larger region, as measured by labor endowments.

(b) The difference in the growth rates of technology development decreases as the elasticity of demand for intermediate goods increases, and it increases as the elasticity of demand for final good increases.

(c) In such an economy, the growth rates of technology development become even between the two regions only if the labor endowments of the two regions are exactly the same. In other words, initial labor endowments are an important factor leading to equal growth rates between the two regions.

The above proposition says that the growth rate of technology development will not be equalized unless the labor endowments of the two regions are exactly the same. In a steady state where $\dot{X}=0$, the difference of the balanced growth rates of technology development implies that the technology development grows faster in the larger region, as measured by labor endowments. The larger region has higher growth rate of technology development, regardless of the degree of elasticity of demand. The elasticity of demand for both intermediate and final goods affects the degree of the difference in the growth rates of technology development between the two regions. The former affects the profit of producing intermediate goods and capital gains through the growth rate of wage, while the latter affects capital gains. As the elasticity of demand for intermediate goods increases, the differences in capital gains and in the profit obtained from producing intermediate goods decrease. The increase in the final good elasticity of demand raises the difference in capital gains. The demand elasticity for the intermediate

\footnotetext{
${ }^{2}$ In a steady state, the balanced growth rate of technology development will become constant and hence the labor devoted to developing new technologies. Since the aggregate labor force available in each region is fixed, labor market clearing condition implies that the aggregate output of intermediate inputs also becomes constant. Therefore $\dot{X}_{k}=0$. If $X_{k}$ is not zero in the steady state, then $\dot{X}_{k}=0$ implies that $\dot{X}_{k} / X_{k}=0$. If $X_{k}$ is zero in the steady state, there is no production of intermediate goods and hence no technology development, so we can rule out the case that $X_{k}$ is zero in the steady state.
} 
goods has a negative impact on the difference in the growth rates of technology development between the two regions, while maintaining a higher growth rate for the larger region, since it reduces the differences both in capital gains and in the profit obtained from producing intermediate goods. When the elasticity of demand for final goods rises the difference in the growth rates of technology development increases proportionally to the difference in the growth rates of wage, boosting the larger region to grow much faster.

Let $\Delta_{k}$ be the share of the initial steady state labor force devoted to developing technologies in region $k$, i.e., $\Delta_{k}=\frac{L_{A, k}\left(t_{s s}\right)}{L_{k}\left(t_{s s}\right)}$. With $\Delta_{k}$, in a steady state where $\dot{X}=0$, equation (17a) can be rewritten as

$$
\frac{\dot{A}_{N}}{A_{N}}=\left[\frac{\Delta_{N}\left[\Delta_{1}-\Delta_{S}\right]}{\Delta_{S}\left[\Delta_{1}-\Delta_{N}\right]}\right] \frac{\dot{A}_{S}}{A_{S}}
$$

In an economy where intermediate goods are not tradable and there are no knowledge spillovers, equation (17b) yields the following proposition 2.

Proposition 2. When the shares of the initial steady state labor allocations of the two regions are the same, the balanced growth rates of technology development are exactly the same in the two regions, that is $\frac{A_{N}}{A_{N}}=\frac{A_{S}}{A_{S}}$ if $\Delta_{N}=\Delta_{S}$. Otherwise, they are uneven.

This proposition implies that the growth rate of technology development must be uneven across regions unless they have the same share of the initial steady state labor force devoted to new technology development. An uneven growth rate of new technology also leads to an uneven growth rate of final goods, as it can be seen in equation (13).

\section{B. Tradable Intermediate Goods}

This section examines an economy in which intermediate goods are traded between the two regions. With tradable intermediate goods, producers of final goods will be better off using their own and the other region's intermediate goods thanks to externality created by input varieties. In this context, this section focuses on an economy where intermediate goods are perfectly traded. Since prices of final goods are equal between the two regions, consumers in each region will choose optimal amount of consumption of final goods produced from the other region equal to that from their own, this is $C_{N}^{j}=C_{S}^{j}$ as in equation (1). With the general equilibrium where all markets clear, the outputs of final goods of the two 
regions are equalized through market clearing condition, because the prices of final goods are equalized. Equation (11) shows that $Y_{N}=Y_{S}$ with $P_{Y, N}=P_{Y, S}$. In addition, because both the outputs and the prices of final goods are equal between the two regions, each region's demand for intermediate goods produced in region $k$ also becomes the same, that is $x_{i, k}^{N}=x_{i, k}^{S}$. Hence, from equation (12c), the relation of aggregate outputs of intermediate goods between the two trading regions becomes $\frac{X_{N}}{X_{S}}=\frac{A_{N}}{A_{N}}\left[\frac{\beta_{M} w_{S}}{\beta_{S} w_{M}}\right]^{\frac{1}{1-\mu}}$. So, the difference in the growth rates of technology development between two regions becomes

$$
\frac{\dot{A}_{N}}{A_{N}}=\frac{\dot{A}_{S}}{A_{S}}+\frac{1}{1-\mu}\left[\frac{\dot{w}_{N}}{w_{N}}-\frac{\dot{w}_{S}}{w_{S}}\right]+\left[\frac{\dot{X}_{N}}{X_{N}}-\frac{\dot{X}_{S}}{X_{S}}\right]
$$

In a steady state where $\dot{X}_{k}=0$, equations (6), (8), (9) and (18) yield the following relation of the growth rates of technology development between the two trading regions

$$
\frac{\dot{A}_{N}}{A_{N}}=\left[\frac{\Delta_{N}\left([1-\mu] \Omega_{N} \Omega_{S}-\Delta_{N} \Delta_{S}\left[1-\delta^{2}\right] \mu A_{N} A_{S}+[1-\mu]^{2}\right) \Omega_{N} \Omega_{S}}{\Delta_{S}\left([1-\mu] \Omega_{N} \Omega_{S}-\Delta_{N} \Delta_{S}\left[1-\delta^{2}\right] \mu A_{N} A_{S}+[1-\mu]^{2}\right) \Omega_{N} \Omega_{S}}\right] \frac{\dot{A}_{S}}{A_{S}}
$$

where $\Omega_{k}=\left[A_{k}+\delta A_{j}\right]$, for $k \neq j$.

In an economy where intermediate goods are tradable, the relation of the growth rates of technology development between the two regions does not depend on the elasticity of demand for final goods. This is because when intermediate goods are tradable, the output of final goods and demand for intermediate goods produced from one region are equal to those form the other region. Also, the amount of the consumption of final goods produced from one region is equal to that from the other region.

When there are no knowledge spillovers, equation (19a) becomes

$$
\frac{\dot{A}_{N}}{A_{N}}=\left[\frac{\Delta_{N}\left[\Delta_{2}-\Delta_{S}\right]}{\Delta_{S}\left[\Delta_{2}-\Delta_{N}\right]}\right] \frac{\dot{A}_{S}}{A_{S}},
$$

where $\Delta_{2}=\frac{1-\mu}{\mu+[1-\mu]^{2}}$, because $A_{k}=\Omega_{k}$.

In an economy where intermediate goods are tradable with perfect knowledge spillovers (i.e., $\delta=1$ ), equation (19a) becomes

$$
\frac{\dot{A}_{N}}{A_{N}}=\left[\frac{\Delta_{N}-\Delta_{N}-\Delta_{S}[1-\mu]}{\Delta_{S}-\Delta_{N}-\Delta_{S}[1-\mu]}\right] \frac{\dot{A}_{S}}{A_{S}}
$$


since $\Omega_{N}=\Omega_{S}$. The above equation immediately yields the following proposition.

Proposition 3: The growth rates of technology development become equal between the two regions if the shares of the initial steady state labor force devoted to developing new technologies are equal between the two regions, that is $\frac{A_{N}}{A_{N}}=\frac{A_{S}}{A_{S}}$ if $\Delta_{N}=\Delta_{S}$. Otherwise, the technology development grows faster in the region with a relatively higher share of the initial steady state labor force devoted to new technology development because $\frac{\dot{A}_{N}}{A_{N}}>(<) \frac{\dot{A}_{S}}{A_{S}}$ depending on $\Delta_{N}>(<) \Delta_{S}$.

In an economy where both regions have equal shares of the initial steady state labor force used for developing new technologies, the growth rates of the two regions will be equal after trade regardless of the degree of knowledge spillovers. Put differently, the even growth rates may not depend on knowledge spillovers but they depend on the fact that two regions have equal shares of the initial steady state labor allocations.

This paper suggests that the even growth rates in knowledge-driven models may be unstable as in Devereux and Lapham (1994). For example, suppose that we consider a different steady state defined by the constant price of new technology development, as in knowledge-driven models. Even though there are no knowledge spillovers (i.e., $\Omega_{k}=A_{k}$ ), we could get the even growth rate of technology development between two regions in a steady state with constant price of new technology development, as it can be seen in equations (15) and (16), regardless of total labor endowments in both regions. ${ }^{3}$ However, we show in proposition 1 that in a steady state where $\dot{X}_{k}=0$, the growth rates of technology development and the wage growth rates become uneven if the effective labor forces available are not the same between the two regions. Therefore, the steady state with constant price of new technology development may be unstable if the labor forces available are not the same in the two regions. Even though we suggest the possibility of instability of the steady state with constant price of new technology development, the condition of the instability is different from that in Devereux and Lapham (1994), because we analyzed a model with different

\footnotetext{
${ }^{3} \mathrm{~A}$ steady state with constant price of new technology development implies that the growth rate of wage rate is equal to the growth rate of technology development. This, in turn, implies that from equation (16), labor force devoted to intermediate goods production becomes constant, because interest rate is constant in a balanced path steady state. The constant labor force devoted to intermediate goods production yields $\dot{X}_{k} / X_{k}=0$ in a balanced path steady state, because $X_{k}=\beta_{k} L_{X, k}$. Hence, equation (15) implies that the growth rates of technology development and the wage growth rate become equal between the two regions, regardless of labor endowments in both regions.
} 
endowments and technologies between the two regions while Devereux and Lapham (1994) considered symmetric endowments.

\section{Welfare}

Can trade in intermediate goods and knowledge spillovers improve welfare? We can analyze the effect of trade in intermediate goods and knowledge spillovers on welfare through an indirect utility function. An indirect utility function is a function of the prices of final goods and consumer's expenditure. Lower prices of final goods and a higher consumer's expenditure lead to a higher welfare in terms of indirect utility. Trade in intermediate goods between the two regions affects the prices of final goods while the degree of knowledge spillovers affects consumers expenditure through the wage rate that affects the productivity of technology development. Those relations imply that trade in intermediate goods and knowledge spillovers improve welfare in both regions. From the price function of final goods given by equation (5), the effect of trade in intermediate goods on the prices of final goods becomes negative. Since an indirect utility function is a decreasing function with respect to the prices of final goods, it is an increasing function with respect to trade in intermediate goods between the two regions. As it can be seen in equation (8), an increase in the degree of knowledge spillovers leads to a rise in the productivity of technology development and hence wage rate. This increased wage rate will also increase the consumer's expenditure, which has a positive effect on indirect utility. Trade in intermediate goods has an externality effect on the production of final goods and thus reduces their prices. Since the prices of final goods become cheaper, consumers will demand more goods. The increased purchasing power improves welfare. With knowledge spillovers, the existing technologies become non-excludable between and within the two regions. Thus the availability of the stock of technologies increases. Because the profit functions for the technology development in both regions are competitive, the increased productivity of technology development due to the increased knowledge spillovers raises the wage rate. This raised wage rate has a positive effect on purchasing power and hence welfare.

The increased growth rates do not mean the equalized economic growth rates. In other words, trade and knowledge spillovers have both level and growth effects, so welfare and economic growth rates may increase even though the levels of welfare and economic growth rates are different between the two regions. 
However, the gap in welfares and economic growth rates between the two regions may deepen if initial endowments between the two regions are not the same, as in initial disparity models.

\section{Conclusion}

In the literature of even growth, the condition for the production function of technology development has been made to validate the even growth with identical production function of technology development and identical labor endowments between the two regions. We should not underestimate the value of the technology development production functions. This paper shows that the growth rates become uneven in an economy where the share of the initial steady state labor allocations between technology development and intermediate inputs are different between the two regions. This paper also shows that trade and knowledge spillovers improve welfare and that they increase the rate of technology development and the consumption rate. Because trade and knowledge spillovers have both level and growth effects, welfare and economic growth rates may increase even though the levels of welfare and economic growth rates are different between the two regions.

This paper analyzes an economy where homogenous labors are not movable across the regions. When labors are movable across the regions and when each region has a different level of human capital, the question of how the labors and human capitals move becomes an important analysis. Furthermore, this paper focuses on the possibility of uneven growth between two trading regions and does not derive the share of the initial steady state labor allocations and the growth rates as a function of economic fundamentals. However, under the assumption of knowledge spillovers and tradable intermediate goods, the initial steady state labor shares could be expressed in parameters of preferences, initial conditions of the levels of technologies, the given endowments, the degree of knowledge spillovers, and the nature of intermediate goods. So, the growth rates can be derived as a function of economic fundamentals. This is an important topic for future research.

Date accepted: July 2001

\section{References}

Azariadis, Costas and Allan Drazen (1990), Threshold Externalities in Economic 
Development, Quarterly Journal of Economics 105, 501-526.

Becker, Gary S., Kevin M. Murphy, and Robert F. Tamura (1990), Human Capital, Fertility and Economic Development, Journal of Political Economy 98, S12-S37.

Boldrin, Michele and Jose A. Scheinkman (1988), Learning by Doing, International trade and Growth: A Note, in SFI Studies in Science of Complexity, Addison-Wesly, Reading MA.

Buiter, Willem H. and Kenneth M. Kletzer (1991), Persistent Differences in National Productivity Growth with a Common Technology and Free Capital Mobility, Journal of the Japanese and International Economy 5, 325-353.

Devereux, Michael B. and Lapham, Beverly J. (1994), The Stability of Economic Integration and

Endogenous Growth, Quarterly Journal of Economics 109, 299-308.

Feenstra, Robert (1996), Trade and Uneven Growth, Journal of Development Economics $49,229-256$.

Goo, Youngwan and Hyun Park (1999), International Imperfect Competition and LongRun Growth, mimeo.

Grossman, Gene M. and Elhanan Helpman (1991), Innovation and Growth in the Global Economy, MIT Press, Cambridge, MA.

Grossman, Gene M. and Elhanan Helpman (1990), Comparative Advantage and Long-run Growth, American Economic Review 80, 796-815.

Krugman, Paul R. (1991), History versus Expectations, Quarterly Journal of Economics 106, 651-667.

Krugman, Paul R. (1987), The Narrow Moving Band, the Dutch Disease, and the Competitive Consequences of Mrs. Thatcher: Notes on Trade in the Presence of Dynamic Scale Economies, Journal of Development Economics 27, 41-55.

Lucas, Romert E. (1988), On the Mechanics of Economic Development, Journal of Monetary Economics 22, 3-42.

Matsuyama, Kiminori (1991), Increasing Returns, Industrialization and Indeterminacy of Equilibrium, Quarterly Journal of Economics 106, 617-650.

Rivera-Batiz, Luis A. and Paul M. Romer (1991a), Economic Integration and Endogenous Growth," Quarterly Journal of Economics 105, 531-555.

Rivera-Batiz, Luis A. and Paul M. Romer (1991b), International Trade with Endogenous Technological Change, European Economic Review 35, 971-1004.

Romer, Paul M. (1990), Endogenous Technological Change, Journal of Political Economy 98, S71-S102.

Segerstrom, Paul S., T. C. A. Anant and Elias Dinopoulos (1990), A Schumpeterian Model of the Product Life Cycle, American Economic Review 80, 1077-1092.

Stokey, Nancy (1991), Human Capital, Product Quality, and Growth, Quarterly Journal of Economics 105, 587-616.

Young, Alwyn (1991), Learning by Doing and Dynamic Effects of International Trade, Quarterly Journal of Economics 106, 365-405. 